\title{
The Beacon Hill Tunnel
}

How a Half-mile of the Boston Subway Was Built in Tunnel

By G. D. Emerson

$\Upsilon_{\text {tion in the Boston district for the use }}^{\mathrm{HE} \text { most recent underground construc- }}$ of street railway traffic is the tunnel through the nearing completion. This tunnel, which is a little less than half a mile in length, does not follow the street lines, but runs through the middle of Beitcon Hill in a general northwesterly an southeasterly direction, connecting at it northwesterly end with an elevated structure which will cross the Cambridge bridg over the Charles River, and at its southeasterly end terminates at present in a station beneath Boston Common, under th Park Street station of the Tremont Stree subway. The bottom of the tunnel, at the deepest point, is about one hundred feet below the top of the hill. This tunnel forms the Boston necting Harvard Square, Cambridge, with the business section of Boston.

Beacon Hill is presumably a glacial formation, and is composed in general of a ver hard mixture of blue and yellow clay an sand, together with numerous small stones and a few large boulders. Irregular streaks and pockets of sand, some containing water, were frequently encountered during the progress of the work. No serious difficulty re sulted, however, from the ground-water, and this, together with the hardness of the ground, made it unnecessary to do any of the work in compressed air, although there was a provision in the contract for the work for doing so in case of necessity. At one point, about sixty-five or seventy feet below the surface, some worn fragments of clam shells were found imbedded in the hard blue clay.

The general method of tunneling adopted for this work was by means of a roof-shield, which is quite similar in character to the shields used in the tunnels already constructed in this vicinity: The Tremon Street tunnel of the original subway, the East Boston tunnel and the Dana Hill tunnel of the Cambridge subway.

This roof-shield is essentially a semi-circular steel frame weighing about sixty-five tons, the diameter of which is equal to the outside width of the tunnel, which is thirtytwo feet four inches. Its function is to sup port the earth above the roof of the tunnel temporarily, while the permanent concrete tunnel arch is being built below.

The first operation in this method of tunneling is to dig two small pilot-tunnelsor so-called side-wall drifts. These drifts are about nine feet squaire, the roof and sides ueing timbered, and they are located at the bottom outside corners of the tunnel sec tion. As fast as they are excavated, the lower part of the concrete side-wall of the tunnel is built in them. They are kept from one hundred and fifty to two hundred feet in advance of the shield, so that the concrete walls will have sufficient time to harden before the weight of the shield comes on them. The shield, which rests on castiron rollers, is pushed along on top of these concrete side-walls by means of hydraulic jacks.

The successive operations are as follows The earth is excavated for two and one-hal feet ahead of the shield, which is the shoved forward through this distance by means of the hydraulic jacks before mentioned. A section of the concrete arch two and one-half feet long is then built under the overhanging steel plates at the rear of the shie!d. The soft concrete is placed on temporary steel centers or supports, which are removed after it has become sufficiently strong. The overhanging plates at the rear of the shield are about one and a quarter inches thick, and when the shield is shoved forward it leaves an annular space of that thickness between the concrete arch and the earth. This space is filled as soon as practicable by pumping in liquid cement grout. In actual work, the operations of excavating

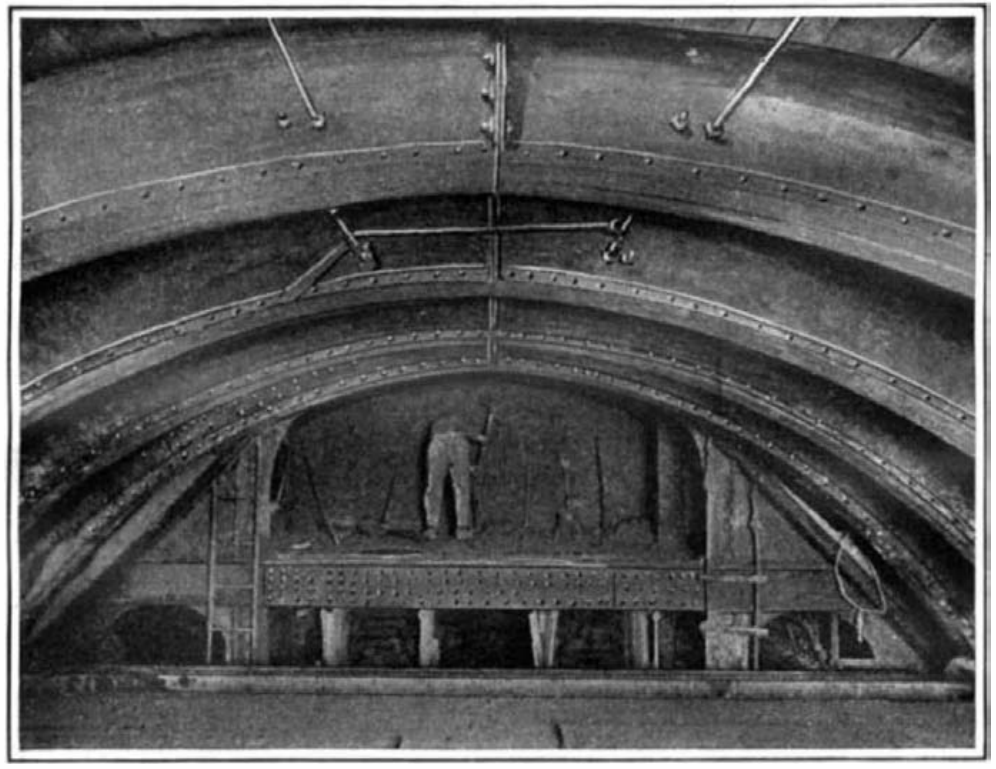

View of steel centers and shield from upper working deck.

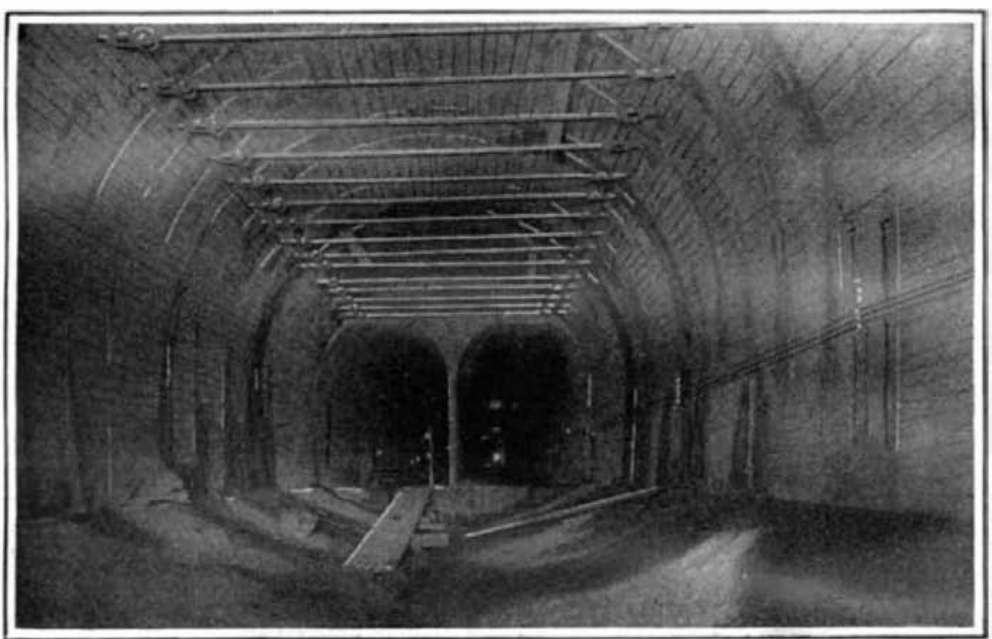

Beacon Hill tunnel looking west toward the twin arches.

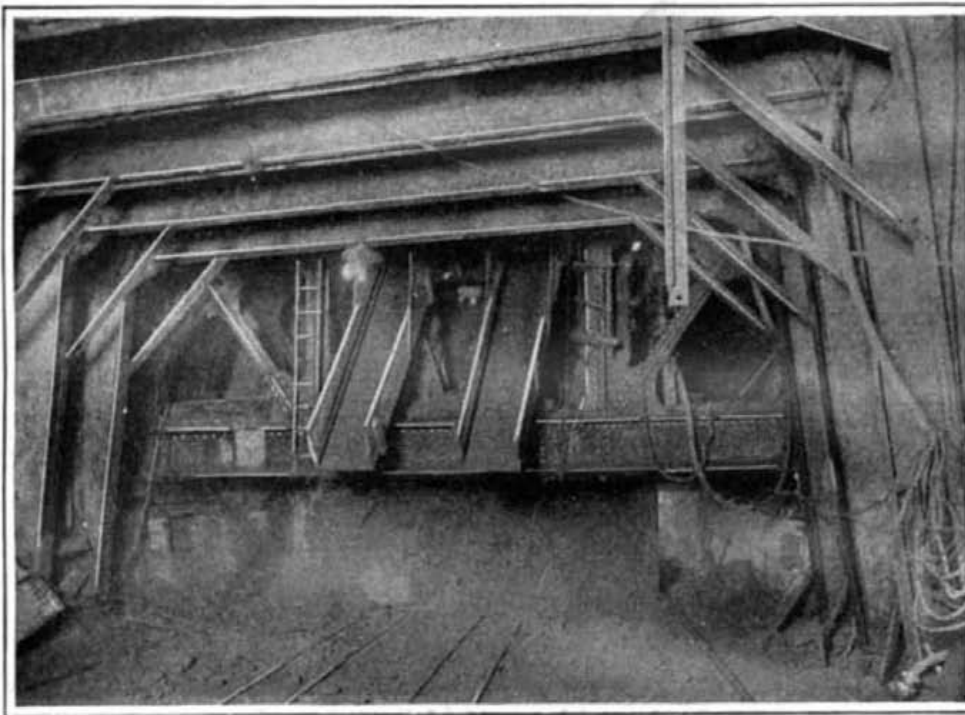

Rear view of lower part of shield, showing temporary steel centering behind it.

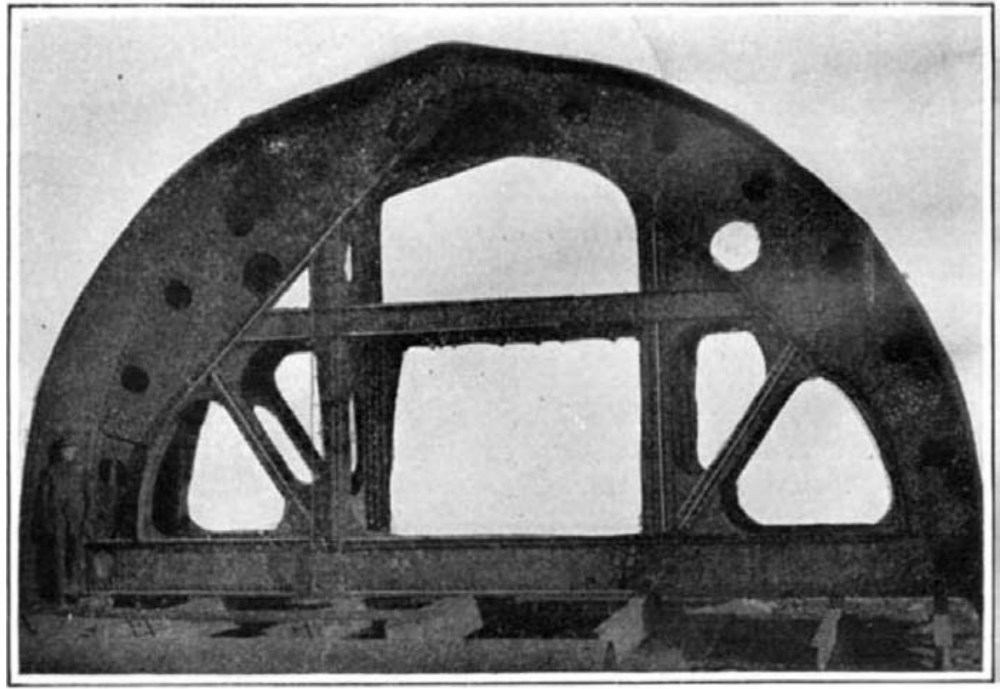

The 65-ton roof-shield used in excavating the tunnel served to hold the earth above roof in place while the permanent concrete arch was being built below it. ahead and putting in concrete at the rear of the shield are carried, on simultaneously. This cycle, which takes about five or six hours, is repeated continiuously.

A rear view of the lower part of the shield in actual operation, and showing some of the temporary steel centering immediately behind it, is shown here/with. The upper half of the shield in working condition is also illustrated. As fast 'as the excavation is completed, and the c.oncrete arch is in place, the concrete bottom is put in.

All machinery for operating the shield and hauling the working-cars in the tunnel is run by compressed aír furnished by a compressor plant located near the mouth of the tunnel. As stated above, the shield is shoved ahead by hydraulic jacks, of which there are fourteen, spaced ioqually around the circumference of the shield. These jacks have plungers eight inches in liameter and work under a maximum pressiure of four thousand pounds to the square inch, which gives a maximum pushing force of nearly one hundred tons for each jack, or about one thousand four hundred tons for the whole shield. The jack-cylindtrs are bolted to the frame-work of the shield and the plungers push against lines of cast. iron rods which are imbedded in the con. crete arch. The water, under pressure, for operating the jacks, is furn shed by two pumps which are run by compressed air.

Economy in this kind of ccnstruction depends to a large extent upon systematizing and specializing the work. Thus, several different gangs of men do the excavating in the pilot tunnels and on the shield platforms, others put in the concrete walls in the pilot tunnels and the concrete arches at the back of the shield, and still others attend to setting up and taking down the temporary concrete supports, handle the cars which bring in fresh concrete and take out the excavated earth, etc. Each of the different operations is repeated continuously so that by proper systematizing the labor becomes very efficient. Most of the work was carried on by two ten-hour shifts per day, the number of men in each shift averaging about one hundred and thirty. The average progress per twenty-four hours was seven and a half feet, and the maximum progress per 24 hours was about nine feet.

The surface of the hill, over the line of the tunnel, is thickly covered with brick buildings from three to six stories in height. The excavation was carried on in such a manner, however, as to avoid any settlement or damage to them.

During the course of the work about a dozen old wells that used to furnish the water supply for former residents on Beacon Hill were encountered in the tunnel head. ings. Some of these old wells were ono hundred feet deep and more than a century old, and the hollow pump-logs were still in place, and in fair condition. The first intimation the tunnel workers had of their ex istence was when the stone lining of the wells fell down into the tunnel when they were reached by the excavations. This resulted in some delays, but no very serious difficulties.

The chief item of interest toward the end of any construction of this sort is where the tunnel "comes out," that is, how close the engineers have been able to run their lines to the theoretical position the tunnel should occupy. Part of this tunnel is on a curve of four-thousand-foot radius, which makes the running of the survey lines somewhat more difficult than if the line were straight. In this particular case the tunnel came out at the final end within less than half an inch of its calculated position.

The Beacon Hill Tunnel is being built for the city of Boston by the Boston Transit Commission, and, upon completion, it will be leased to the Boston Elevated Railway Company. 